\title{
A study on school health policies and programs in the southeast of Iran: a regression analysis
}

Fariba Shahraki-Sanavi ${ }^{1}$, Fatemeh Rakhshani², Alireza Ansari-Moghaddam ${ }^{3}$, Mahdi Mohammadi ${ }^{4}$

${ }^{1} \mathrm{PhD}$ Student of Health Education \& Promotion, Health Promotion Research Center, Public Health Department, Zahedan University of Medical Sciences, Zahedan, Iran

${ }^{2}$ Professor of Health Education, Safety Promotion and Injury Prevention Research Center (SPIPRC), School of Public Health, Shahid Beheshti University of Medical Sciences, Tehran, Iran

${ }^{3}$ Professor of Epidemiology, Health Promotion Research Center, Epidemiology \& Biostatistics Department, Zahedan University of Medical Sciences, Zahedan, Iran

${ }^{4}$ Associate Professor of Statistic, Health Promotion Research Center, Epidemiology \& Biostatistics Department, Zahedan University of Medical Sciences, Zahedan, Iran

\section{Type of article: Original}

\begin{abstract}
Background: Investing in adolescent health is one of the most important interventions in the health system. Accordingly, health-promoting schools organize their policies, methods, infrastructures, and activities towards protecting and promoting the health and well-being of the students, teachers, directors, authorities and society as a whole.

Objective: To study the health policies of schools in the southeast of Iran.

Methods: This cross-sectional study was carried out on all governmental high schools (113 schools) which were enrolled by census sampling method in January 2017, in Zahedan, in the southeast of Iran. The study tool was a validated questionnaire about the "School Health Policies and Programs" that was completed by the principals or staff of the schools. Data were analyzed by SPSS version 15, using descriptive statistic and linear regression test.

Results: About one-third of the schools did not have a health educator. Some policies, including annual medical examinations, having a healthy breakfast at school, healthy food supply at lower prices in school buffets, and counseling the students with special conditions in schools were not implemented. The most inter-sectoral cooperation was among the health centers $(47.8 \%)$. The mean score of health policy implementation in schools was $89.70 \pm 11.51$. Linear regression analysis demonstrated a significant relationship between type of school $(\mathrm{p}<0.05)$ and number of students in schools as well as attendance of a health educator in schools $(\mathrm{p}<0.001)$ with health policies

Conclusions: Despite the implementation of the program in Iran in recent years, there are no clear and identical policies in the schools. Therefore, there is need to establish health policy committees in schools from among staff, teachers, parents, and students. In addition, success of the program requires inter-sectoral collaboration, supporting environmental health and improvement of parents' relationships with the school.
\end{abstract}

Keywords: Health policy, High school, Iran, country

\section{Introduction}

Policy-making is a dynamic, complex, political process (1). Health policy-making has a significant role in the health sector due to the specific nature of this division compared with other social aspects (2). In the health system, changing the policies is very challenging because the change in part of this complex system inevitably affects other

\section{Corresponding author:}

Professor Dr. Alireza Ansari-Moghaddam, Doctor Hesabi Square, Zahedan University of Medical Sciences, ZIP Code: 9817667993. Tel: + 98915541 2155, Email: ansarialireza@yahoo.com.

Received: July 29, 2017, Accepted: September 20, 2017, Published: July 2018

iThenticate screening: August 21, 2017, English editing: March 15, 2018, Quality control: May 14, 2018

This article has been reviewed / commented by four experts

Funding / research project approval: Grant no.: 2772 (Zahedan University of Medical Sciences)

Ethics approval: IR.ZAUMS.REC.1394.251

(C) 2018 The Authors. This is an open access article under the terms of the Creative Commons Attribution-NonCommercialNoDerivs License, which permits use and distribution in any medium, provided the original work is properly cited, the use is non-commercial and no modifications or adaptations are made. 
sectors and many of its various workers and beneficiaries (3). Health policy-making can be integrated into four levels. The first level of policy-making interventions targets long-term structural changes; the second level targets the development of living conditions through public strategies within frameworks; the third level targets strengthening social support for targeted individuals; and the fourth level targets influential individual attitudes and habits (4). Furthermore, the health promotion approach is implemented through various strategies, the most important of which is the environments approach. Then, school environments are among the priority for health promotion interventions in the $21^{\text {st }}$ century (5). Accordingly, health-promoting schools (HPS) across the world are recognized as having a multifaceted approach that can support healthy behaviors. Global studies report high levels of support for the HPS approach (5). The WHO framework introduces HPS as organized policies, methods, infrastructures, and activities that protect and upgrade health and well-being of students, teachers, principals, parents and the community (6). HPS is a health promotion system that increases capacities and empowers people with healthy living, healthy work, and quality education, through the active participation of parents, teachers, and students, and with the approach of empowering students in caring for themselves, self-care culture, and peer education. HPS includes eight common components, each of which can be evaluated by policy-making and studying the skills at schools (7). Organization and specialized interventions include an active strategy for rebuilding the physical and social environment of schools through education, training, modeling and motivating health promotion. School-based interventions also support the prevention of chronic diseases and cancers if they target multiple environmental and behavioral dimensions in a complementary strategy in society. HPS supporters are taking healthimproving steps that affect social norms, improve access to resources, and support healthy behaviors (5). The idea of health promoting schools was introduced and initiated around the world in 1978 (8). In line with the global movement, Iran has also been establishing health promoting programs in public schools throughout the country, since 2010 (9). Health promotion beneficiaries align schools with managing and relying on health promotion principles, along with prioritizing health in school decisions and plans (10).

It is noteworthy that school policies can play a key role in health development. School policies ensure the allocation of resources and the implementation of school activities and practices, and highlight school priorities (11). In comparison, the lack of health-centered policies in schools causes instability and variability of school programs for health promotion. These policies are designed at national, provincial, local, and school levels and should be in proportion to each other. In addition, the sustainability of the HPS program and its positive effects depend on the continued participation and cooperation of a wide range of beneficiaries in the community. To this end, it is essential to maintain the direct, active and continuous participation of the beneficiaries within and outside the health sector for successful inter-sectoral programs (12). Furthermore, if current school policies are reviewed and school-based health-centered policies are redefined, they provide a basis for the full commitment of beneficiaries within the school and provide an executive guarantee in terms of resource allocation and school priority. This requires a comprehensive commitment by the education system of the countries to pay close attention to the health outcomes associated with educational decisions and establishing health promotion laws for students in different dimensions (13). In addition, the literature on health promotion emphasizes that the sustainability of health promotion programs depends on the fact that changes beyond the individual level include organizational and institutional changes, too (14). In this regard, new studies on the awareness of the effectiveness of the health school model have discussed the comprehensive school approach $(13,15)$. To our knowledge, no study has identified the policies of Health Promoting Schools in Iran. Therefore, the present study was carried out to investigate health promotion policies in high schools in the southeast of Iran.

\section{Material and Methods}

\subsection{Setting and participants}

The present cross sectional study was conducted in January 2017 in Zahedan, Iran. After coordinating with the Ministry of Education to conduct the study, 113 high schools were enrolled by census sampling method and informed consent was obtained from the participants in the study.

\subsection{Instrument and data colelction}

Data were collected by a self-report questionnaire, which was based on a policy-making questionnaire introduced by CDC (Global School Health Policies and Practices Study 2015). The items of the questionnaire were modified based on the rules and regulations in the educational system of Iran. The final questionnaire consisted of 70 items with a content validity ratio of 0.83 , content validity index of 0.97 and internal consistency (Cronbach's Alpha) of 0.73 . The questionnaires were completed either by the school principals or by staff. Then, data were collected via questionnaires and reports (15 items), and health promotion interventions including examinations, counseling, 
workshops, and classes (26 items). At the beginning of data collection step, a brief description of the study purpose, as well as instruction of the questionnaire, was given to the school principal. In addition, the method of answering the questionnaire was explained to the participants. The minimum and maximum scores were 64 and 128 , respectively. The allocated time to complete the questionnaire was 30-45 minutes.

\subsection{Statistical analysis}

The collected data was analyzed by SPSS version 15 (SPSS Inc., Chicago, Illinois, USA), using descriptive statistic and linear regression analysis. P-value of less than 0.05 was considered as a statistically significant level.

\subsection{Research ethics}

The subjects were entered into the study, observing ethical and voluntary codes. The ethics of the study were approved by the research ethics committee of Zahedan University of Medical Science (Ref. No.: IR.ZAUMS.REC.1394.251).

\section{Results}

The present cross sectional study was conducted on 113 high schools (44 female and 69 male) in the southeast of Iran, Zahedan. The number of students ranged from 60 to 761 in schools. The weaknesses include the absence of a committee or health policy team, the lack of active participation of trained people, no web page for health education, no annual medical examinations, no hearing screening, no breakfast-eating policy and not providing healthy food at lower prices, and no consultation for students with a high BMI. Furthermore, 29.2\% of schools lacked health educators. In total, the health educators were attending school on an average of $2.59 \pm 1.63$ days per week. The highest cooperation in the implementation of health activities in schools was related to the health centers (with nearly 50\%), physical education organization, municipality and provincial government, respectively (Table 1). Overall, the mean score of school health policies was $89.70 \pm 11.51$. The results of regression analysis showed positive significant relationship between the types of schools, the number of students in the schools and the attendance of the health educator with health policies $\left(\mathrm{R}^{2}: 0.25, \mathrm{~F}: 12.62, \mathrm{p}<0.001\right)$.

Table 1. Frequency of inter-sectoral cooperation of other organizations with the Education Department in the health promotion programs of high schools

\begin{tabular}{|l|l|}
\hline Organization & $\mathrm{n}(\%)$ \\
\hline Provincial Government & $10(8.8)$ \\
\hline Municipality & $10(8.8)$ \\
\hline Physical Education Organization & $12(10.6)$ \\
\hline Health center of the province or city & $54(47.8)$ \\
\hline Other organizations (State Welfare Organization, Red Crescent, Police, etc.) & $15(13.3)$ \\
\hline Total & $12(10.6)$ \\
\hline
\end{tabular}

\section{Discussion}

The results of this study revealed that schools lack a uniform definition for health policies, a health team or committee, health education during the academic year, and training courses for staff and teachers in line with this program. Furthermore, the degree of inter-sectoral and intra-sectoral cooperation in implementing school healthpromotion policies was underprivileged. Meanwhile, structural and environmental changes in schools require a supportive approach from the beneficiaries outside the school at national and provincial policy-making levels. In addition, parents' and teachers' participation in school health programs was poor. Creating widespread interactions between schools and the local community is important in developing an approach to health promoting schools. This requires support and participation of parents of students using the structural capacities of the Parents and Teachers Association. In addition, poor physical infrastructure in schools was due to the lack of adequate financial support and human resources to improve this infrastructure at the school level (16). A Fathi et al. study on HPS in northwestern Iran, demonstrated that the main barriers and challenges were related to inter-sectoral cooperation, politics and law, infrastructures and capacities, human resources and social participation. They concluded that the current version of the program has fundamental gaps. In order to succeed in achieving the objectives of the HPS, it is necessary to reassess the macro plan of the program and issue effective and practical policies and strengthen the support of program implementation and program preservation in schools based on the country's capacities and goals (17). On the other hand, evidence suggests that a uniform structure, representing different beneficiaries, is essential for managing, designing, organizing, coordinating and facilitating the program. This structure makes the scattered structures and resources to be shared and ensures the intra-sectoral collaboration at different national, provincial, and 
local levels, in particular, the collaboration of the school with the local community (8). In a study in Babol, Iran, Ramezani et al. reported that the continuity and support of the program by the Ministry of Education and involving the authorities of schools and health centers could significantly improve the health indices of schools (8). In the present study, the results showed that the highest cooperation was related to health centers. While schools that can establish a strong communication network with diverse beneficiaries in the social environment will succeed in the implementation of the program and bring positive results, and continuity of these networks will maintain health promotion activities at school.

Different studies have been conducted on the experiences of different countries in promoting health schools, each of which has led to different outcomes and challenges. One of the most important tasks in the implementation phase of the plan in the United States was the mobilization of facilities and human resources and the use of all players including policymakers, public and private sectors, students, teachers and parents together as a whole (18). Furthermore, the major issues listed by European countries were the need to strengthen cooperation between the education, health, technical and support divisions, as well as an adequate budget (19). A systematic study of the implementation of health promotion programs in schools in the UK has identified the conditions and actions that have contributed to the successful implementation of school health-promotion programs with the help of a team of high-level officials, university professors, and health and education specialists. The results of studies have defined four theories including preparation for the implementation of counseling before the presentation of measures, the development of the program in each school, the inclusion of the program in the routine activities of schools, and the correct implementation and compliance with the program. Ultimately, these theories were revised and modified using national assessments (20). Generally, the components of promoting the health schools approach and the mechanism of each component, illustrated that eight components are essential to implement the approach of health promoting schools, including planning, preparing, political and organizational support, students' participation, networking, partnerships and sustainability of the programs. The effectiveness of the approach also depends on the complete implementation and coverage of all these components (21).

In their study, mean scores of policies, activities, and interventions in boy's schools were higher than in girl's schools, and regression tests showed a significant difference between them. Also, according to the regression model, attendance of the health educator had the greatest impact on policy implementation. This finding showed the importance of paying more attention to female schools and employing full-time health educators in schools. In line with the results of this study, HPS program is a multifactorial approach, that includes the three pillars of major health-oriented structural and environmental modifications in school, development of an educational and health curriculum, and strengthening the dynamic interaction between the school and the local community (parents and various beneficiaries outside the school) in line with school and community health promotion. This approach seeks to make changes in the school structure beyond behavioral changes. The program's success in countries largely depends on the predisposing factors, design, and implementation, using evidence-based approaches and executive commitment $(10,22)$. The limitations of this study were that only public schools were included. Secondly, collected data are based on school administrators' reports. Therefore, it is suggested to carry out comprehensive studies at the provincial and national levels to examine and analyze the health policies of schools, and provide practical and applicable solutions for reforming national policies accordingly.

\section{Conclusions}

It can be concluded that in the first pillar of designing a health and education curriculum, designing and revising the national curriculum, and designing comprehensive health education standards in different grades in the formal educational system of Iran are necessary. Talented and skilled human resources are also needed at schools to develop the concept of health and health-related priority for an executive guarantee of this program. Therefore, applicable planning is necessary for improving the health conditions of students. In fact, planning is preparing a ground for a series of strategic decisions (such as setting priorities) or doing some specific executive activities or analysis of a wide range of information.

\section{Acknowledgments:}

This article was part of the Ph.D. thesis. This Study was funded by Zahedan University of Medical Sciences (Grant no.: 2772). Therefore, authors would like to express their gratitude to Zahedan University of Medical Sciences, the Health Promotion Research Center, the District Department of Education and the school heads, teachers and students who helped conduct this study. 


\section{Conflict of Interest:}

There is no conflict of interest to be declared.

\section{Authors' contributions:}

The overall implementation of study design, data management and analysis and manuscript preparation were the results of joint efforts by multiple individuals who are listed as co-authors of this paper. All authors read and approved the final manuscript.

\section{References:}

1) Buse K, Mays N, Walt G. Making health policy. UK: McGraw-Hill Education; 2012.

2) Collins C, Green A, Hunter D. Health sector reform and the interpretation of policy context. Health Policy. 1999; 47(1): 69-83. doi: 10.1016/S0168-8510(99)00003-2.

3) Buse K, Mays N, Walt G. Making health policy (understanding public health). UK: Bell \& Brain Ltd; 2005.

4) Whitehead M, Dahlgren G, Gilson L. Developing the policy response to inequities in health: A global perspective. Challenging inequities in health: From ethics to action. New York: Oxford University Press. 2001: 309-23.

5) Goodburn EA, Ross DA. Young people's health in developing countries: a neglected problem and opportunity. Health Policy and Planning. 2000; 15(2): 137-44. doi: 10.1093/heapol/15.2.137.

6) Inman DD, van Bakergem KM, Larosa AC, Garr DR. Evidence-based health promotion programs for schools and communities. Am J Prev Med. 2011; 40(2): 207-19. doi: 10.1016/j.amepre.2010.10.031. PMID: 21238871.

7) Barrios LC, Burgeson CR, Crossett L, Harrykissoon SD, Pritzl J, Wechsler H, et al. School Health Index: A Self-Assessment and Planning Guide. Middle School/High School. US Department of Health and Human Services. 2004.

8) Ramezani H, Nikbakht H, Nasrollahpour Shirvani S, Ahoei K, Mohsenian H. Effect of Health Promoting School Program in Schools of the City of Babol: 2013. Journal of Health. 2015; 6(5): 547-56.

9) Yazdi Feyzabadi V, Keshavarz Mohammadi N, Omidvar N, Karimi-Shahanjarini A, Nedjat S, Rashidian A. Factors associated with unhealthy snacks consumption among adolescents in Iran's schools. Int J Health Policy Manag. 2017; 6(9): 519-28. doi: 10.15171/ijhpm.2017.09.

10) Inchley J, Muldoon J, Currie C. Becoming a health promoting school: evaluating the process of effective implementation in Scotland. Health Promotion International. 2007; 22(1): 65-71. doi: 10.1093/heapro/dal059. PMID: 17178755.

11) Viner RM, Ozer EM, Denny S, Marmot M, Resnick M, Fatusi A, et al. Adolescence and the social determinants of health. The lancet. 2012; 379(9826): 1641-52. doi: 10.1016/S0140-6736(12)60149-4.

12) Larsen M, Rantala R, Koudenburg OA, Gulis G. Intersectoral action for health: The experience of a Danish municipality. Scand J Public Health. 2014; 42(7): 649-57. doi: 10.1177/1403494814544397. PMID: 25074270.

13) Stewart D, McWhirter J, Rowe F, Stewart D, Patterson C. Promoting school connectedness through whole school approaches. Health Education. 2007; 107(6): 524-42. doi: 10.1108/09654280710827920.

14) Swerissen H, Crisp BR. The sustainability of health promotion interventions for different levels of social organization. Health promotion international. 2004; 19(1): 123-30. doi: 10.1093/heapro/dah113. PMID: 14976180.

15) Stewart D, McWhirter J, Sun J, Stewart D. How effective is the health-promoting school approach in building social capital in primary schools? Health Education. 2007; 107(6): 556-74. doi: 10.1108/09654280710827948.

16) Larson N, DeWolfe J, Story M, Neumark-Sztainer D. Adolescent consumption of sports and energy drinks: linkages to higher physical activity, unhealthy beverage patterns, cigarette smoking, and screen media use. Journal of nutrition education and behavior. 2014; 46(3): 181-7. doi: 10.1016/j.jneb.2014.02.008. PMID: 24809865, PMCID: PMC4023868.

17) Fathi B, Allahverdipour H, Shaghaghi A, Kousha A, Jannati A. Challenges in Developing Health Promoting Schools' Project: Application of Global Traits in Local Realm. Health promotion perspectives. 2014; 4(1): 9. PMID: 25097832, PMCID: PMC4122035.

18) Ippolito-Shepherd J. Health-promoting schools initiative in the Americas. UN chronicle. 2005; 60(2): 1521. 
19) Barnekow Rasmussen V, Rivett D. The European Network of Health Promoting Schools-an alliance of health, education and democracy. Health Education. 2000; 100(2): 61-7. doi: 10.1108/09654280010312397.

20) Pearson M, Chilton R, Wyatt K, Abraham C, Ford T, Woods HB, et al. Implementing health promotion programmes in schools: a realist systematic review of research and experience in the United Kingdom. Implementation Science. 2015; 10: 149. doi: 10.1186/s13012-015-0338-6. PMID: 26510493, PMCID: PMC4625879.

21) Marks R, Samdal O, Rowling L. Theoretical and empirical base for implementation components of healthpromoting schools. Health Education. 2011; 111(5): 367-90. doi: 10.1108/09654281111161211.

22) Parsons $C$, Stears D, Thomas C. The health promoting school in Europe: conceptualising and evaluating the change. Health Education Journal. 1996; 55(3): 311-21. doi: 10.1177/001789699605500306. 